\title{
Comparison of brachial and central blood pressures using an oscillometric device with 2 or 6 metre tubing lengths for assessment of central pressure during MRI exam
}

\author{
Sebastian Stroer ${ }^{1,2}$, Gilles Soulat ${ }^{1,2^{*}}$, Sébastian Tavolaro ${ }^{1,2}$, Sandrine Millasseau ${ }^{3}$, Hakim Khettab ${ }^{1,2}$, \\ Pierre Boutouyrie $^{1,2}$, Stéphane Laurent ${ }^{1,2}$, Elie Mousseaux ${ }^{1,2}$
}

From 19th Annual SCMR Scientific Sessions

Los Angeles, CA, USA. 27-30 January 2016

\section{Background}

Magnetic resonance imaging (MRI) offers the possibility to measure local and regional indices of aortic function. However calculations of these indices usually require blood pressure (BP) values. Up to now, because of its easier availability, brachial BP was used instead of local aortic pressure. The SphygmoCor Xcel system (AtCor Medical, Australia) estimates aortic pressure noninvasively. It consists in a MRI compatible brachial cuff connected via a hose to a recording unit and computer. The aim of this study was to compare brachial and central $\mathrm{BP}$ values given by SphgymoCor Xcel with the standard 2 meters hose and a 6 meters hose more suitable for central BP assessment during MRI.

\section{Methods}

After 5 min rest supine, BP was measured simultaneously on both arms with one $2 \mathrm{~m}$ SphgymoCor Xcel and one $6 \mathrm{~m}$ SphgymoCor Xcel. Arms were randomly assigned. Tubing were then interchanged (cuffs unchanged) and recordings repeated.

\section{Results}

38 patients were studied (63\% men). Seven (18\%) were treated for hypertension, 2 (5\%) for diabetes and $3(11 \%)$ for dyslipidaemia. Median age was 36.8 years (28.5-58.4). Brachial Systolic BP (SBP), Diastolic BP (DBP), Pulse Pressure (PP), central SBP, DBP PP, augmented pressure (AP) and augmentation index (Aix) from the $2 \mathrm{~m}$ and $6 \mathrm{~m}$ device were strongly correlated $\left(\mathrm{R}^{2}=0.96,0.91,0.78,0.97\right.$, $0.85,0.95,0,96$ respectively, $\mathrm{p}<0.001$ for all.). Bland Altman plots showed no statistical difference between 2 and $6 \mathrm{~m}$ for brachial and central SBP, DBP, PP values. However there was a difference between AP and Aix recorded with $2 \mathrm{~m}$ and $6 \mathrm{~m}$ hose $(-2.65 \pm 1.5 \mathrm{mmHg}$, $\mathrm{p}=0.043$ and $-5.25 \pm 2.93 \%, \mathrm{p}=0.038$ respectively).

\section{Conclusions}

SphygmoCor Xcel device with a $6 \mathrm{~m}$ hose, brachial and central BP shows no statistical difference with the standard $2 \mathrm{~m}$ hose, allowing data to be collected during MRI exams. However other parameters using waveform morphology such as AP and Aix are not so reliable.

\section{Authors' details}

${ }^{1}$ European Hospital Georges Pompidou, Paris, France. ${ }^{2}$ PARCC INSERM U970 Paris Descartes University, Paris, France. ${ }^{3}$ Pulse Wave Consulting, St Leu, France.

Published: 27 January 2016

doi:10.1186/1532-429X-18-S1-P20

Cite this article as: Stroer et al:: Comparison of brachial and central blood pressures using an oscillometric device with 2 or 6 metre tubing lengths for assessment of central pressure during MRI exam. Journal of

Cardiovascular Magnetic Resonance 2016 18(Suppl 1):P20.

European Hospital Georges Pompidou, Paris, France

Full list of author information is available at the end of the article

(c) 2016 Stroer et al. This is an Open Access article distributed under the terms of the Creative Commons Attribution License (http:// creativecommons.org/licenses/by/4.0), which permits unrestricted use, distribution, and reproduction in any medium, provided the original work is properly cited. The Creative Commons Public Domain Dedication waiver (http://creativecommons.org/publicdomain/ zero/1.0/) applies to the data made available in this article, unless otherwise stated. 